\title{
Adoption and diffusion of technical capacity-building innovations by small- scale artisanal fishers in Fiji
}

\author{
$\underline{\text { Tracy MacKeracher }}^{1,2}$ Simon J. Foale $^{3}$, Georgina G. Gurney $^{4}$ and Steven W. Purcell $^{1}$
}

\begin{abstract}
Adoption of innovations by farmers and fishers can depend on factors specific to both individuals and their social contexts. Research on the adoption and diffusion of innovations promoted through capacity-building training can provide lessons to support the design and implementation of future development programs. We assess the adoption, diffusion, and outcomes of a livelihoods training program focused on improving postharvest handling and processing of sea cucumbers in 29 coastal villages in Fiji. One year after delivery of the training program, we conducted interviews with sea cucumber fishers $(n=278)$ and commercial processors $(n=12)$, as well as focus group discussions $(n=27)$ with women to examine: $(1)$ which modes of training (training video, manual, and workshops) were most useful; (2) individual- and community-scale characteristics related to adoption and knowledge sharing; (3) whether training produced long-term changes in processing methods used by fishers; and (4) perceived barriers to adoption. Among fishers who were exposed to two or more modes of training $(n=97)$, most $(65 \%)$ reported the workshop and manual to be equally useful. Knowledge about the improved methods was shared by $71 \%$ of trained fishers and occurred more frequently among women $(80 \%)$ than men (64\%). Trained fishers used shorter, less variable first cooking durations than untrained fishers, and differences were significant for two of six sea cucumber species groups. Adoption and knowledge sharing was not significantly related to the multiscale characteristics examined (age, gender, education, resource dependence, village population size, market access). Some fishers could not access salt for processing, and others were constrained by patron-client relationships. Our study shows that technical capacity-building can benefit from complementary training modes, however other constraints on adoption (e.g., access to materials, patron-client relationships) may need to be addressed to achieve the full benefits of training programs.
\end{abstract}

Key Words: capacity-building; diffusion of innovations; gender; sea cucumbers; small-scale fisheries

\section{INTRODUCTION}

Small-scale fisheries can contribute to reducing poverty in developing countries (Béné et al. 2007). Consequently, the past two decades have seen widespread implementation of donorfunded development projects aiming to improve livelihoods by increasing fisher income (e.g., FAO Regional Fisheries Livelihoods Programme 2013). Many overseas-aid funded projects rely on information-based approaches, with interventions designed to improve incomes by providing access to new information about resource harvesting, processing, or management. However, given a lack of adoption of new information or innovations, defined as a new or improved idea, practice, or technology (Rogers 2003), many of these interventions have not led to sustained changes in fisheries livelihood practices (see Barclay and Kinch 2013). With smallscale fisheries under considerable and increasing pressure from both local and global-scale threats (Cinner et al. 2013, Kittinger et al. 2013), there is a pressing need to improve our understanding of the factors influencing adoption of innovations promoted by livelihood development interventions.

Livelihood development interventions must be designed and implemented to maximize adoption. Empirical research in the agricultural sector has applied diffusion of innovation theory to explore adoption of innovations (e.g., Krause et al. 2007, Matata et al. 2010, Lowitt et al. 2015). This and other work has demonstrated that adoption of innovations can be related to characteristics of individuals (e.g., resource dependence, age, gender, education level) and their communities (e.g., population size, leadership, proximity to markets; see Aguilar-Gallegos et al. 2015, Meijer et al. 2015, Barry 2016).

Most livelihood development programs have relatively short project cycles and limited geographic reach. Success thus often relies on innovation diffusion through social networks. Through this process, adopters, i.e., individuals applying new technology/ methods in their own practices, share new information with others in their community (MacVaugh and Schiavone 2010). However, whether or not knowledge is shared may be related to individual characteristics such as gender, age, and access to dissemination tools. For example, mobile phones are common among rural Papua New Guineans and are now a key mode for information exchange (Curry and Koczberski 2013, Curry et al. 2016). Understanding the characteristics of knowledge sharers could help to target and tailor future training programs in a way that maximizes their potential effectiveness.

This study aimed to assess adoption and dissemination of a livelihoods development program focused on improving postharvest handling and processing of sea cucumbers in Fiji. Owing to high demand from Asian markets for sea cucumber in its dried form (bêche-de-mer; Purcell et al. 2018), sea cucumbers were reported to be the second-most valuable export fishery in the South Pacific (Carleton et al. 2013). Sea cucumbers represent an important income source for many small-scale fishers in the

\footnotetext{
${ }^{1}$ National Marine Science Centre, Southern Cross University, Coffs Harbour, New South Wales, Australia, ${ }^{2}$ Centre for Tropical Water and Aquatic Ecosystem Research, James Cook University, Townsville, Queensland, Australia, ${ }^{3}$ College of Arts, Society and Education, James Cook University, Townsville, Queensland, Australia, ${ }^{4}$ Australian Research Council Centre of Excellence for Coral Reef Studies, James Cook University, Townsville, Queensland, Australia
} 
Oceania region (Kinch et al. 2008, Barclay et al. 2016, Purcell et al. 2016a); most of the approximately 300,000 fishers in the region can be classed as small-scale (Purcell et al. 2013). However, relative to the end-market value of sea cucumbers, the price offered to fishers is often low (Purcell et al. 2017). A key factor influencing the price offered to fishers is postharvest handling and processing quality (Kinch et al. 2008, Ram et al. 2014, Mangubhai et al. 2017). Thus, improving sea cucumber handling and processing represents a potential opportunity to improve the livelihoods of small-scale fishers in this region.

We explore adoption and diffusion of a training program aimed at improving sea cucumber harvesting and processing by fishers in 29 villages in Fiji. We conducted fisher surveys one year after delivery of the training program to examine: (1) which among three modes of training (training video, manual, and village-based workshops) were considered most useful; (2) individual- and community-scale characteristics related to adoption and knowledge sharing of the new methods; (3) perceived barriers to adoption; and (4) whether the processing methods used differed between trained and untrained fishers. This research offers lessons to support the design and implementation of future capacitybuilding interventions for improving livelihoods in small-scale fisheries.

\section{METHODS}

\section{Study sites and fishery context}

We studied 29 coastal communities located across 7 island subregions of Fiji (Fig. 1). Communities were selected in consultation with fishery managers from the Fiji Ministry of Fisheries, who provided advice regarding where fishers were collecting sea cucumbers. Estimates from experienced exporters indicated that around 8000 fishers were collecting sea cucumbers in Fiji. To capture a broad representation of the sea cucumber fishery, we selected communities across a wide geographic range irrespective of the intensity of fishing effort and postharvest processing frequency. All communities were governed by a village chief and organized by an administrative village headman (a turaga ni koro). Permission to collect data was gained through a formal authorization process (sevusevu) with chiefs of each village.

Resource management systems were similar among locations, with marine tenure systems of customary rights (qoliqolis) restricting harvest of marine resources in certain areas (Govan 2009). At the time of study, up to 27 species of sea cucumber were harvested by gleaning, breath-hold diving, and, in villages with exemption permits, scuba diving (Purcell et al. 2016b). Harvested sea cucumbers could be sold fresh to a commercial processor or exporter, or processed by fishers and later sold as dried bêche-demer. Postharvest processing involves (1) cutting the animals at a specific location on the body to remove their guts; (2) cooking the animals in hot or boiling water; (3) optional smoke and/or saltcuring; and, often, (4) cooking the product a second time before drying it in the sun until nearly fully dried (Fig. 2). The ideal parameters for each of these steps vary among species groups. Prior to the training program evaluated by this study, the processing methods used by fishers were often substandard in comparison to the methods used by commercial processors and exporters (Ram et al. 2014, Purcell et al. 2016c).
Fig. 1. Map of Fiji with the 7 locations (annotated) and the 29 study communities (green squares).

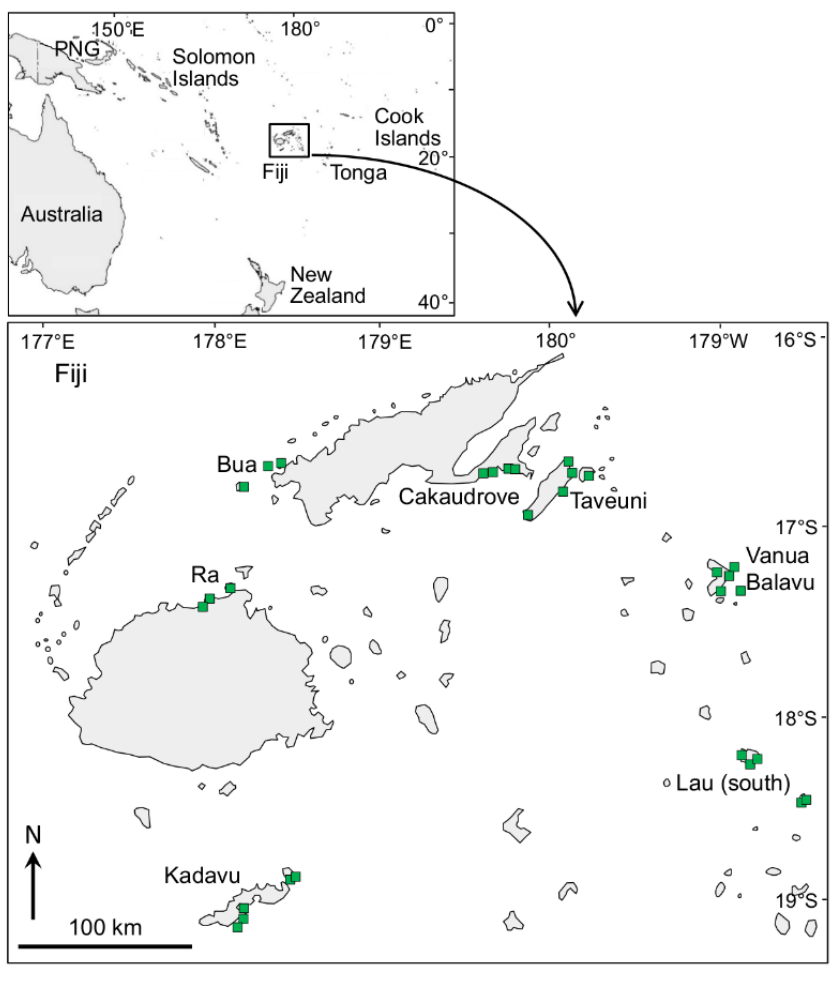

Fig. 2. Photos depicting capacity building, data collection, and fishers with processed sea cucumbers in Fiji: (a) a training workshop at Taveuni, (b) a focus-group discussion session with women at Vanua Balavu, (c) a fisher in the southern Lau Group with dried sea cucumbers, (d) a woman fisher at Kadavu with processed sea cucumbers, (e) a questionnaire-based interview of a fisher at Vanua Balavu, (f) a fisher with a black teatfish (Holothuria whitmaei) being salt cured, (g) fisher cooking sea cucumbers in village on Vanua Balavu. Photos a, g: W. Lalavanua; photos b, c, d, e, f: S. Purcell.

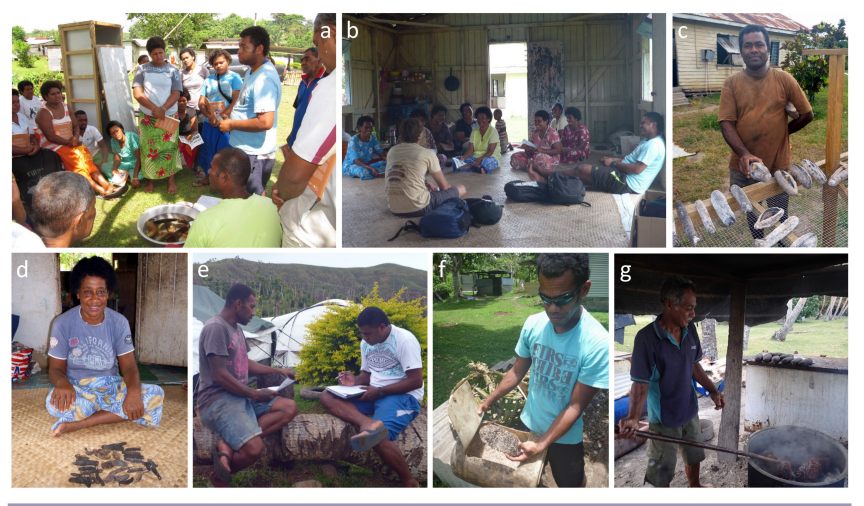

A livelihoods training program was implemented in each of the 29 study communities from September 2014 to July 2015. The 
Table 1. Descriptions of the dependent variables (knowledge sharing and adoption) and independent variables (individual- and community-scale characteristics) used to explore adoption and diffusion of methods promoted in a training program on postharvest processing of sea cucumbers. $\mathrm{FS}=$ fisher surveys; $\mathrm{VH}=$ village headmen surveys.

\begin{tabular}{|c|c|c|c|}
\hline Variable & Description & Type & Method \\
\hline Diffusion & Whether fishers shared knowledge gained from training $(\mathrm{Yes}=1, \mathrm{No}=0)$ & Dichotomous & FS \\
\hline Adoption & Whether trained fishers changed their methods $($ Yes $=1$, No $=0)$ & Dichotomous & FS \\
\hline Population & Number of people living in the community & Count & $\mathrm{VH}$ \\
\hline Market access & Number of bêche-de-mer buyers to which community has access & Count & $\mathrm{VH}$ \\
\hline Age & Age of fisher, in years & Count & FS \\
\hline Gender & Gender & Dichotomous & FS \\
\hline Education & Number of years of school education & Count & FS \\
\hline Dependence & $\begin{array}{l}\text { Whether sea cucumbers are the only marine resource caught and sold commercially (Yes } \\
=1, \mathrm{No}_{\mathrm{O}}=0 \text { ) }\end{array}$ & Dichotomous & FS \\
\hline
\end{tabular}

program used 3 modes of training: (1) a 44-page training manual (Purcell 2014); (2) a 21-minute training video; and (3) villagebased workshops. The manual and video, developed through interviews with commercial processors, illustrated improved methods on how to handle and process different sea cucumber species to export quality. The training video was available online on YouTube and institutional websites, and one DVD version was given to each village for passing around to fishers via the village headman or the local fishery officer (Processing sea cucumbers: $a$ training DVD for Pacific Island fishers; Online English version: http://www.youtube.com/watch?v=KH6u0oZoclk; Online Fijian

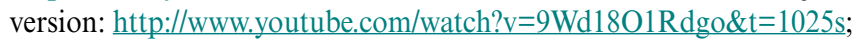
Downloadable files: http://scu.edu.au/environment-scienceengineering/index.php/125). The hands-on workshops took 11/2 days, during which fishers brought their catch and were shown every handling and processing step. Each training mode explained the range of appropriate cooking durations (10-30 min.) and salt curing durations (2-5 days) for different species groups.

\section{Survey methodology and data collection}

From November 2015 to September 2016, approximately one year after delivery of the training program, each village was revisited to collect data on adoption and diffusion of the training. We conducted semistructured questionnaire-based interviews with 278 sea cucumber fishers, including both (1) fishers who had never been exposed to any training (hereafter untrained), and (2) fishers who had been exposed to one or more modes of training. We selected respondents using convenience and snowball sampling, applying a gender inclusive approach (Kleiber et al. 2015) by interviewing women whenever possible to ensure their representation in the surveys (Appendix 1, Table A1.1). Surveys were designed to collect information on (1) which training mode was considered most useful; (2) individual fisher characteristics (i.e., age, gender, education level, dependence on sea cucumbers); (3) potential barriers to adoption; and (4) processing methods used by fishers. Community-scale data were obtained through semistructured surveys with 29 village headmen (Table 1; Fig. 2).

To obtain qualitative information on the perceived usefulness and consequences of the program, we conducted semistructured questionnaire-based interviews with 12 commercial processors and held focus-group discussion sessions with village women (1) who were involved in sea cucumber harvesting and/or processing themselves, or (2) whose spouses were involved in sea cucumber harvesting and/or processing (Fig. 2). We were unable to hold focus-group sessions in two of the villages because of other obligations of villagers. We acknowledge that the quantity and reliability of qualitative information obtained from these sessions might be reduced due to the fact that (1) the sessions were facilitated by men; (2) attendance was lower than intended (average of four women per session); and (3) women were often eager to return to their daily work.

\section{Data analysis}

We used hierarchical linear models to assess whether adoption and, separately, knowledge sharing by trained fishers could be predicted by six multiscale characteristics (Table 2). To account for the clustered structure of our data (i.e., fishers nested within villages, villages nested within locations) we a priori set location and village as random effects. This ensured more accurate estimation by imposing a correlation structure on data collected from the same village. Adoption and knowledge sharing were modeled as dichotomous dependent variables, with trained fishers classified based on whether they had changed their methods following the training $(0=$ nonadopter, $1=$ adopter $)$, and whether they had shared knowledge about the new methods $(0=$ knowledge not shared, $1=$ knowledge shared). Collinearity among independent variables was assessed (Appendix 1), and continuous independent variables were standardized by subtracting their mean and dividing by two of their standard deviations to gauge their relative importance as the relative magnitude of their effect sizes. We used Bayesian estimation with weakly informative prior distributions (Appendix 1), the default recommended for hierarchical linear models with a binary dependent variable (Gelman et al. 2008).

We used hierarchical linear models to test whether trained and untrained fishers used different processing methods for the six sea cucumber species groups: Actinopyga spp., Bohadschia spp., lollyfish and pinkfish (Holothuria edulis and H. atra), Stichopus spp., teatfish (Holothuria fuscogilva and $H$. whitmaei), and Thelenota spp. During semistructured interviews with fishers, we collected information on the methods used in five important handling and processing steps: (1) cut location; (2) water temperature at first cooking; (3) salt curing duration; (4) first cooking duration; and (5) second cooking duration (Table 2). Cut location and water temperature were modeled as dichotomous dependent variables, with fishers classified based on whether they used the correct starting temperature for first cooking $(1=\mathrm{cool} /$ warm; $0=$ hot/boiling) and whether they used the correct cut 
Table 2. Summary of Bayesian hierarchical linear models.

\begin{tabular}{|c|c|c|c|c|}
\hline Dependent variable & Independent variable(s) & $\begin{array}{l}\text { Model error } \\
\text { distribution }\end{array}$ & Fisher sample & Sample size \\
\hline knowledge sharing & $\begin{array}{l}\text { population size } \\
\text { market access } \\
\text { age } \\
\text { gender } \\
\text { education level } \\
\text { dependence }\end{array}$ & binomial & trained only & 53 \\
\hline adoption & $\begin{array}{l}\text { population size } \\
\text { market access } \\
\text { age } \\
\text { gender } \\
\text { education level } \\
\text { dependence }\end{array}$ & binomial & trained only & 46 \\
\hline cut location & training & binomial & all & $29-36$ \\
\hline water temperature & training & binomial & all & 81 \\
\hline salt curing & training & gaussian & all & $22-42$ \\
\hline first cook & training & gaussian & all & $33-62$ \\
\hline second cook & training & gaussian & all & $21-41$ \\
\hline
\end{tabular}

location for Thelenota spp. $(1=$ ventral; $0=$ other $)$ and teatfish ( $1=$ dorsal; $0=$ other $)$. We only examined whether training was related to cut location for teatfish and Thelenota spp. because optimal cut location for these species is quite specific and standardized in the marketplace, and because it influences the quality/value of the final product. Salt curing and cooking durations were modeled as continuous dependent variables. In all models, training (trained vs. untrained) was treated as a categorical fixed effect, with location and village treated as random effects. Sample sizes for each of the models are outlined in Table 2. Analyses were conducted using R software (R Core Team 2018).

\section{RESULTS}

\section{Perceived usefulness of training}

Of the 278 fishers surveyed, $46 \%$ had been exposed to 1 or more modes of training; $90 \%$ of trained fishers had received a manual and $80 \%$ had attended a workshop, while only $20 \%$ had watched the video. The English version of the training video and two other Pacific Island language versions (Kiribati and Tongan) attracted high view counts on YouTube but the Fijian version did not. We discovered that some fishery officers and village headmen had not passed around the training DVDs that we had left in their care, and as a result many fishers were unaware of them. Among trained fishers, most $(76 \%)$ had received two or more forms of training (e.g., they received a manual and attended a workshop). Of these, $5 \%$ reported the manual as being the most useful, $29 \%$ found the workshop to be most useful, and $1 \%$ reported the DVD to be most useful; the rest $(65 \%, n=64)$ reported the workshop and manual to be equally useful.

Characteristics associated with adoption and knowledge sharing Among trained fishers surveyed $(n=128), 36 \%$ responded about whether they had changed their methods following the training, with most $(89 \%)$ reporting that they had. Although adoption occurred more frequently among men $(96 \%)$ than women $(80 \%)$, differences were not significantly related to individual or village- scale characteristics (Fig. 3a). Among trained fishers who responded about knowledge sharing $(n=56)$, most $(71 \%)$ reported passing on knowledge about the new processing methods. Although knowledge sharing occurred more frequently among women $(80 \%)$ than men $(64 \%)$, our analyses indicate that knowledge sharing did not differ significantly with gender, nor any of the other multiscale characteristics examined (Fig. 3b).

\section{Comparison of processing methods used by trained and untrained} fishers

Among the 278 fishers surveyed, 30\% were processing the sea cucumbers they harvested, while the remaining $70 \%$ were selling raw products to commercial processors. Among fishers who reported to be processing their catch $(n=82)$, we found that trained fishers $(n=53)$ did not differ significantly from untrained fishers $(n=29)$ with respect to whether they (1) cut teatfish correctly; (2) cut Thelenota species correctly; and (3) used the correct starting water temperature for cooking (Appendix 1, Table A1.3). First-cooking durations were less variable and shorter (on average) for trained fishers compared to untrained fishers, however differences were only significant only Bohadschia spp. and pinkfish/lollyfish (Fig. 4a; Appendix 1, Table A1.3). Many of the untrained fishers used excessively long cooking times in comparison to the best-practice durations (dashed lines, Fig. 4a). Trained fishers used more appropriate salt curing and second cooking durations (i.e., longer salt curing, shorter cooking) than untrained fishers, on average (Fig. 4b, c). However, the durations were highly variable among fishers and thus did not differ significantly between trained and untrained fishers for any of the six species groups (Fig. 4b, c; Appendix 1, Table A1.3).

During the time at the end of the interviews for volunteered comments, eight fishers asked if there could be follow-up workshops or commented that follow-up visits about processing should be held, one of whom suggested biennially. Women in two focus-group sessions also gave unsolicited comments that they wanted further workshops on processing. 
Fig. 3. Individual- and community-scale (underlined) socioeconomic characteristics and their relationship to (a) adoption of new methods by trained fishers $(n=46)$; and (b) knowledge sharing by trained fishers $(\mathrm{n}=53)$. Parameter estimates are highest posterior density medians (black dots) and associated $95 \%$ uncertainty intervals (UIs), estimated from Bayesian hierarchical linear models. Estimates to the right of the dashed line indicate that the variable was positively related to adoption or knowledge sharing. Reference category: Gender, "Female"; Dependence, "No".
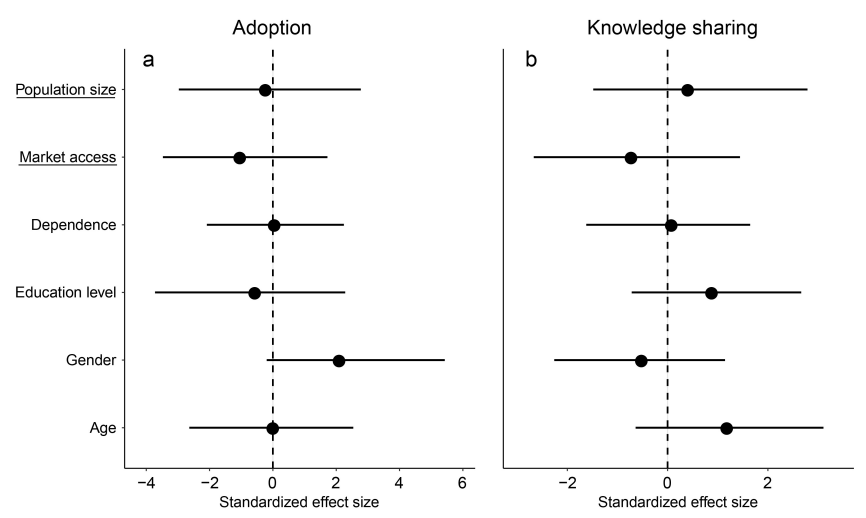

\section{Perceived barriers to adoption}

Many fishers $(n=39)$ reported problems in applying the new methods, and 11 reported more than 1 problem. Lack of access to coarse salt for salt-curing was the most commonly cited barrier to adoption, reported by 33 fishers. This issue was also raised in four focus group sessions, with women reporting that they had not implemented the new processing methods because they were unable to purchase coarse salt. Other issues highlighted were the lack of access to a smoker $(n=3)$, the cost of salt $(n=2)$, the failure to receive higher prices for their better-processed product $(n=1)$, and buyer preference for the unprocessed product $(n=2)$. Five fishers mentioned at the end of interviews that they would like to do more processing, but that they did not have the required equipment.

\section{Other outcomes of training}

Among trained fishers responding about a change in time spent processing their catch $(n=46)$, the majority $(67 \%)$ said they spent the same or less time processing their catch than before the training. An increase in time spent processing was reported more frequently among women $(42 \%)$ than men $(26 \%)$. Although fishers who reported spending more time on processing $(n=15)$ claimed that the quality of their bêche-de-mer product had improved, some $(n=8)$ mentioned that the extra time took time away from other important activities, in particular, socializing, resting, and/or family time. This issue was also raised in five of the focus groups, with some women commenting that applying the new methods left them with less time for cooking, weaving, household chores, socializing, and spending time with family.

Among the commercial processors surveyed ( $n=12), 83 \%$ reported that the program had been good for the industry; the key reason provided was that processing methods had improved
Fig. 4. Differences in sea cucumber (a) first cooking duration; (b) salt curing duration; and (c) second cooking duration among trained (blue bars) and untrained (yellow bars) fishers across six harvested species groups: Bohadschia spp. (Boh), Actinopyga spp. (Act), teatfish (Teat), lollyfish and pinkfish (L \& P), Thelenota spp. (The), and Stichopus spp. (Sti). Dashed lines indicate the minimum and maximum cooking durations considered appropriate for a particular species group. Salt curing was an optional processing step, with a recommended duration of between two and five days.
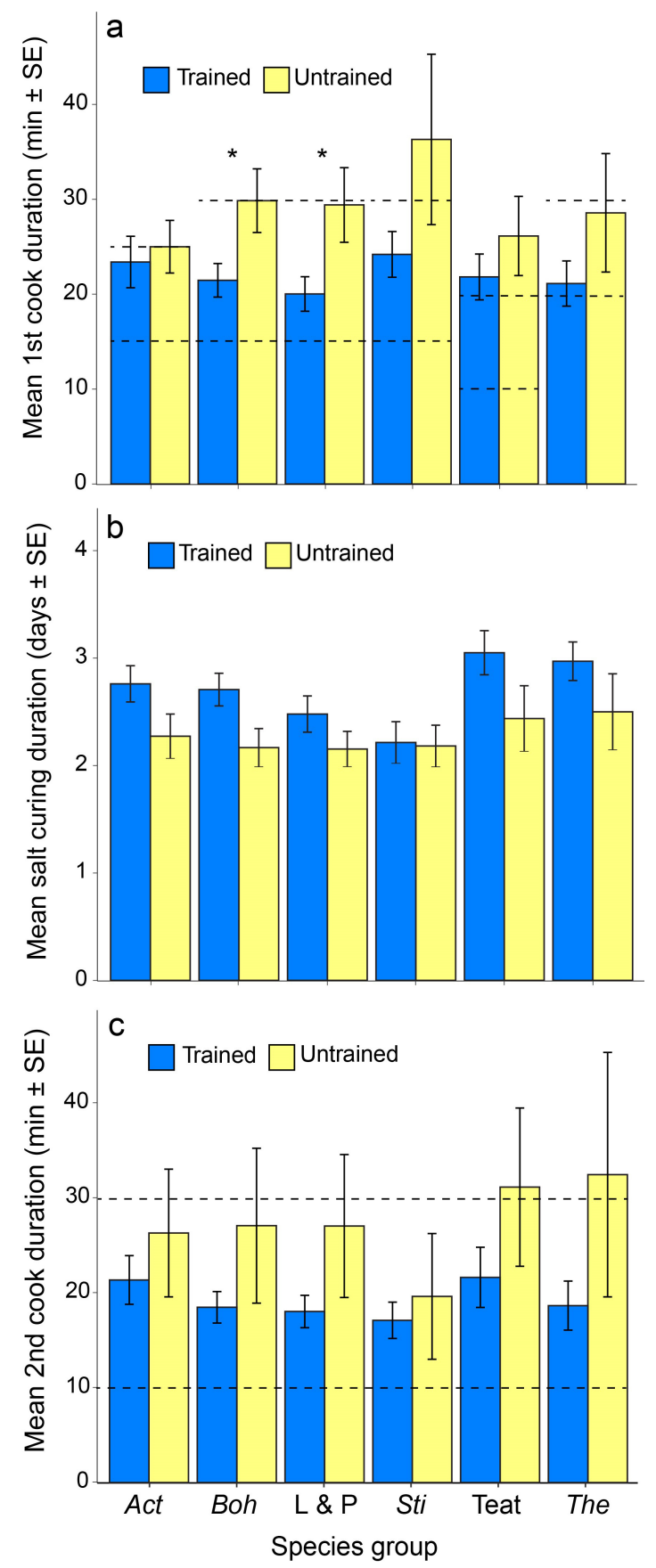
as a result of the training. The two processors who believed that the training hadn't affected the industry said that this was because they were still buying mostly unprocessed sea cucumbers and conducting most or all the processing themselves. This is consistent with explanations by some fishers and by women in two focus groups, specifically, that many fishers rely on processors to supply a boat and fuel, and in return must sell their raw catch directly to the commercial processors.

\section{DISCUSSION}

\section{Perceived usefulness of training}

Most fishers who had been exposed to two or more modes of training found the manual and workshop to be equally useful, suggesting complementarity of these training modes. Employing multiple modes of communication is a hallmark of strategic communication aimed at behavior change because the various forms of communication can be employed for different purposes and feasibility is context dependent (Santucci 2005). We posit that the workshop might have been particularly useful for introducing the new processing methods with a limited number of sea cucumber species, while the manual provided information for the full range of fished species and could be referred to repeatedly.

A surprisingly small proportion of respondents considered the training video and DVD to be most useful, a finding which offers lessons for future programs. The power of images to convey complex messages across cultural and linguistic boundaries is well recognized (Foale 2013, Bucchi and Saracino 2016), yet fewer people than we expected had access to watch the DVD or viewed the videos online. The failure of some village headmen and fishery officers to distribute the DVDs suggests that future programs should organize viewing sessions in villages instead of relying on intermediaries to pass on training materials.

\section{Characteristics associated with adoption and knowledge sharing}

Rural Pacific Islanders are well known for their rapid adoption of new technologies, species, or cultivars that deliver (or are believed to deliver) increased farming or fishing yields (Macintyre and Foale 2013). Examples of relatively recent fishing innovations include a modified dredge for harvesting sea cucumbers (Christensen 2011), and lights combined with gill nets for harvesting small pelagic fishes from dugout canoes at night (Roeger et al. 2016). Previous studies found relationships between adoption and diffusion of innovations and various socioeconomic characteristics of individuals and their communities (e.g., Aguilar-Gallegos et al. 2015, Meijer et al. 2015, Barry 2016). Our analyses indicate that adoption was not significantly related to the multiscale socioeconomic characteristics examined, with the possible exception of gender. Variation in adoption may thus be driven by other factors not captured in our analysis. Indeed, we found that adoption was constrained by access to materials, value-chain problems (such that better-processed products did not result in higher buying prices), and existing patron-client arrangements that required fishers to sell unprocessed sea cucumbers. Future programs may therefore benefit from preliminary research to understand the factors relevant to adoption in a given context, so that the adoption and spread of innovations can be maximized.

Although a higher percentage of women shared knowledge about the new methods compared to men, our analysis indicated that knowledge sharing was comparable between men and women and was not significantly related to the other characteristics examined. Work by Thomas and Caillon (2016) on the sharing of valuable plant cultivars suggests that social status may influence the degree to which valuable knowledge is shared. Further, other likely factors of importance are the ease with which (1) new processing methods can be directly observed by others (Macintyre and Foale 2013), and (2) the benefits for adopters are discernible and/or communicated by them.

\section{Processing methods used by trained and untrained fishers}

We found that cooking durations used by trained fishers were shorter (on average) and less variable than untrained fishers, but only significantly shorter for two of six sea cucumber species groups. There are likely various reasons why some fishers did not adopt this change and/or retain it over the long term. Repeated training (i.e., follow-up visits) could perhaps promote more fishers to retain the processing methods in the long term. Similarity in salt curing durations between trained and untrained fishers is likely attributed to the fact that before the training, Fijian fishers were already generally salting their sea cucumbers for a suitable number of days (average across species 2.4-3.3 days; Purcell et al. $2016 c$ ), so the methods promoted in the training did not represent a marked departure from the status quo.

Observed gender differences in the reported changes in time taken to process sea cucumbers following the training interventions are intriguing. Women might have been focussing more on those aspects of processing that required an increased time investment, such as smoking and salting. This increased workload, or just the "perception" of increased workload, to apply the new methods could limit adoption by villagers. Future capacity building of fishers could benefit from more qualitative research to understand differences in workloads and available time.

\section{Barriers to adoption and other lessons learned}

Lack of access to salt was apparently a key barrier to adoption. This was partly because many fishers misunderstood that salt curing was an optional (but recommended) processing step. The lack of access to salt might be best resolved with the assistance of national fisheries ministries, who could source the salt at cost price and sell it to fishers through regional fishery offices. However, even if salt could be made available to fishers, the immediate time and financial cost of constructing salting boxes, may cause people to discount future benefits from improved prices. In this case, repeated trainings might impart a stronger impression of the benefit in terms of improved sale prices (mainly due to increased weight) relative to the cost, and the difficulty, of obtaining salt.

Adoption of the processing methods promoted in the training may have been constrained by sociocultural factors that were not captured in our quantitative analysis. For example, our qualitative data revealed that many fishers relied on commercial processors to provide a boat and fuel, and in exchange had to sell their harvest directly to processors. Such patron-client relationships might constrain adoption of innovations, and could explain why a relatively small percentage of fishers $(30 \%)$ were processing their own catch into bêche-de-mer. Adoption may be further constrained by an unwillingness to invest the necessary time and resources if other activities are perceived to be more useful or important (Curry et al. 2015). Therefore, livelihood development 
programs might need to also consider broader economic and sociocultural factors that may hinder or facilitate adoption of technical capacity-building innovations.

\section{Critiques, caveats, and future directions}

Our approach taken to attribution was to compare sea cucumber processing methods employed by those who had and had not participated in the training at a single point in time. This approach relies on three assumptions: (1) prior to the training, there were no differences between future participants and nonparticipants with respect to factors that could influence outcomes; (2) that untrained fishers were not exposed to knowledge gained by other fishers who participated in the training; and (3) there were no contemporaneous factors that were correlated with the project and that could affect outcomes (Ferraro 2009). Given we cannot test these assumptions with our data, our ability to attribute any differences in processing practices employed by trained and untrained fishers to the training is curtailed.

A further limitation is that we relied on self-reported (rather than observed) data. Research on human behavior often relies on selfreporting (e.g., Agrawal and Gupta 2005, Gurney et al. 2016), but discrepancies between reported and observed behavior can occur (Armitage and Conner 2001). This is common if the respondent perceives that the interviewer desires certain responses, potentially leading to social desirability bias. Triangulating data from multiple sources (including focus groups with fishers and sea cucumber buyers) provided us with some insight into potential discrepancies. Research is underway to examine the broader socioeconomic and ecological impacts of this capacity-building program.

When communicating information to promote changes in behavior, the messenger is often as important as (or more important than) the message (Foale 2013). Indeed, the presence of opinion leaders has been shown to influence adoption (Blythe et al. 2017). Thus, the effectiveness of development programs aiming to improve livelihoods may be enhanced by partnering with members of the target communities who are well-connected, respected, and influential within their community. Once identified, these individuals could play a role in implementation of capacity-building programs by facilitating or leading training activities (e.g., workshops).

\section{CONCLUSION}

This study intentionally involved a training (intervention) stage, a one-year period of adoption, and a multilevel assessment aimed at informing the design of future programs to maximise innovation adoption and diffusion. Although the minority of trained fishers reported that they adopted new processing methods, there were consistent differences (albeit generally not statistically significant) between trained and untrained fishers with respect to cooking durations, a key factor in proper processing. Variation in adoption among trained fishers was not related to the socioeconomic characteristics we examined, suggesting that other factors influence adoption. We found that adoption of new processing methods was constrained by factors including access to materials, value-chain problems (such that better-processed products did not result in higher buying prices), and existing patron-client arrangements. Multiple training modes appear to be useful for these small-scale fishers, however the utility of training videos might be country specific. Our study emphasizes that capacity-building is just one part of livelihood development, and that achieving long-term adoption of innovations might require continued training, support to fishers for access to materials, and initiatives to develop alternative relationships with traders.

Responses to this article can be read online at: http://www.ecologyandsociety.org/issues/responses. $\mathrm{php} / 10777$

\section{Acknowledgments:}

This study was funded by the Australian Centre for International Agricultural Research (ACIAR) through project FIS/2010/096. We thank Chris Barlow for guidance of the research. We acknowledge and thank Watisoni Lalavanua and Sailasa Tagica for assistance with data collection and entry. Support was also provided by Southern Cross University, Ministry of Fisheries Fiji, Partners in Community Development Fiji, and the Pacific Community (SPC).

\section{LITERATURE CITED}

Agrawal, A., and K. Gupta. 2005. Decentralization and participation: the governance of common pool resources in Nepal's Terai. World Development 33:1101-1114. https://doi. org/10.1016/j.worlddev.2005.04.009

Aguilar-Gallegos, N., M. Muñoz-Rodríguez, H. Santoyo-Cortés, J. Aguilar-Ávila, and L. Klerkx. 2015. Information networks that generate economic value: a study on clusters of adopters of new or improved technologies and practices among oil palm growers in Mexico. Agricultural Systems 135:122-132. https://doi. org/10.1016/j.agsy.2015.01.003

Armitage, C. J., and M. Conner. 2001. Efficacy of the theory of planned behaviour: a meta-analytic review. British Journal of Social Psychology 40:471-499. https://doi.org/10.1348/014466601164939

Barclay, K., and J. Kinch. 2013. Local capitalisms and sustainability in coastal fisheries: cases from Papua New Guinea and Solomon Islands. Pages 107-138 in F. McCormack and K. Barclay, editors. Engaging with capitalism: cases from Oceania. Emerald Group, Bingley, UK. https://doi.org/10.1108/S0190-1281 (2013)0000033007

Barclay, K., J. Kinch, M. Fabinyi, S. Waddell, G. Smith, S. Sharma, P. Kichawen, S. Foale, and R. Hamilton. 2016. Interactive governance analysis of the bêche-de-Mer 'Fish Chain' from Papua New Guinea to Asian markets. University of Technology, Sydney, Australia. [online] URL: https://www.uts. edu.au/sites/default/files/2019-02/png-bdm-interactive-governancereport_0.pdf

Barry, S. 2016. The determinants of adoption of improved varieties of sesame in northern Burkina Faso. Asian Journal of Agriculture and Rural Development 6:163. https://doi. org/10.18488/journal.1005/2016.6.9/1005.9.163.173 
Béné, C., G. Macfadyen, and E. H. Allison. 2007. Increasing the contribution of small-scale fisheries to poverty alleviation and food security. Food and Agriculture Organization of the United Nations (FAO), Rome, Italy. [online] URL: http://www.fao.org/3/ a0965e/a0965e00.pdf

Blythe, J., R. Sulu, D. Harohau, R. Weeks, A.-M. Schwarz, D. Mills, and M. Phillips. 2017. Social dynamics shaping the diffusion of sustainable aquaculture innovations in the Solomon Islands. Sustainability 9:126. https://doi.org/10.3390/su9010126

Bucchi, M., and B. Saracino. 2016. "Visual science literacy" images and public understanding of science in the digital age. Science Communication 38:812-819. https://doi.org/10.1177/107$\underline{5547016677833}$

Carleton, C., J. Hambrey, H. Govan, P. Medley, and J. Kinch. 2013. Effective management of sea cucumber fisheries and the bêche-de-mer trade in Melanesia. SPC Fisheries Newsletter 140:24-42. [online] URL: http://www.nautilus-consultants.co.uk/ sites/default/files/FishNews140 24 Carleton.pdf

Christensen, A. E. 2011. Marine gold and atoll livelihoods: the rise and fall of the bêche-de-mer trade on Ontong Java, Solomon Islands. Natural Resources Forum 35:9-20. https://doi. org/10.1111/j.1477-8947.2011.01343.x

Cinner, J. E., N. A. Graham, C. Huchery, and M. A. MacNeil. 2013. Global effects of local human population density and distance to markets on the condition of coral reef fisheries. Conservation Biology 27(3):453-458. https://doi.org/10.1111/ j.1523-1739.2012.01933.x

Curry, G. N., E. Dumu, and G. Koczberski. 2016. Bridging the digital divide: everyday use of mobile phones among market sellers in Papua New Guinea. Pages 39-52 in M. Robertson, editor. Communicating, networking: interacting. Springer, Cham, Switzerland. https://doi.org/10.1007/978-3-319-45471-9 5

Curry, G. N., and G. Koczberski. 2013. Development implications of the engagement with capitalism: improving the social returns of development. Pages 335-352 in F. McCormack and K. Barclay, editors. Research in economic anthropology, engaging with capitalism: cases from Oceania. Emerald Group, Bingley, UK. https://doi.org/10.1108/S0190-1281(2013)0000033015

Curry, G. N., G. Koczberski, J. Lummani, R. Nailina, E. Peter, G. McNally, and O. Kuaimba. 2015. A bridge too far? The influence of socio-cultural values on the adaptation responses of smallholders to a devastating pest outbreak in cocoa. Global Environmental Change 35:1-11. https://doi.org/10.1016/j. gloenvcha.2015.07.012

FAO Regional Fisheries Livelihoods Programme. 2013. Regional Fisheries Livelihoods Programme for South and Southeast Asia ( GCP/RAS/237/SPA). FAO, Rome, Italy. [online] URL: http:// www.fao.org/fishery/rflp/en

Ferraro, P. J. 2009. Counterfactual thinking and impact evaluation in environmental policy. Pages 75-84 in M. Birnbaum and P. Mickwitz, editors. Environmental program and policy evaluation: addressing methodological challenges. New directions for evaluation. Wiley, New York, New York, USA. https://doi. org/10.1002/ev.297
Foale, S. J. 2013. Fish and people: an innovative fisheries science learning tool for the Pacific. SPC Traditional Marine Resource Management and Knowledge Information Bulletin 31:21-24. [online] URL: https://spccfpstore1.blob.core.windows.net/digitallibrarydocs/files/c5/c5813cf5ee9d7a538dc19d98af80363a.pdf?sv=2015-12-11\&sr= b\&sig $=q f 2 \mathrm{Lzo} \% 2 \mathrm{FbsaUZdvgpehW4UkqjPFUmxwFNa8B3JA8 \%}$ 2BGU4\%3D\&se $=2019-09-10 \mathrm{~T} 17 \% 3 \mathrm{~A} 09 \% 3 \mathrm{~A} 27 \mathrm{Z} \& \mathrm{sp}=\mathrm{r} \& \mathrm{rscc}=\mathrm{public} \%$ 2C $\% 20$ max-age $\% 3 \mathrm{D} 864000 \% 2 \mathrm{C} \% 20$ max-stale $\% 3 \mathrm{D} 86400 \&$ rsct $=$ application $\% 2$ Fpdf\&rscd $=$ inline $\% 3 \mathrm{~B} \% 20$ filename $\% 3 \mathrm{D} \% 22 \mathrm{Trad} 31$. pdf $\% 22$

Gelman, A., A. Jakulin, M. G. Pittau, and Y.-S. Su. 2008. A weakly informative default prior distribution for logistic and other regression models. Annals of Applied Statistics 2(4):1360-1383. https://doi.org/10.1214/08-AOAS191

Govan, H. 2009. Status and potential of locally-managed marine areas in the South Pacific: meeting nature conservation and sustainable livelihood targets through wide-spread implementation of LMMAs. SPREP/WWF/WorldFish-Reefbase/CRISP, Noumea, New Caledonia. [online] URL: https://mpra.ub.uni-muenchen. de/23828/1/MPRA paper 23828.pdf

Gurney, G. G., J. E. Cinner, J. Sartin, R. L. Pressey, N. C. Ban, N. A. Marshall, and D. Prabuning. 2016. Participation in devolved commons management: multiscale socioeconomic factors related to individuals' participation in community-based management of marine protected areas in Indonesia. Environmental Science and Policy 61:212-220. https://doi.org/10.1016/j.envsci.2016.04.015

Kinch, J., S. Purcell, S. Uthicke, and K. Friedman. 2008. Papua New Guinea: a hot spot of sea cucumber fisheries in the Western Central Pacific. Pages 55-57 in V. Toral-Granda, A. Lovatelli, and M. Vasconcellos, editors. Sea cucumbers: a global review of fisheries and trade. FAO, Rome, Italy.

Kittinger, J. N., E. M. Finkbeiner, N. C. Ban, K. Broad, M. H. Carr, J. E. Cinner, S. Gelcich, M. L. Cornwell, J. Z. Koehn, X. Basurto, R. Fujita, M. R. Caldwell, and L. B. Crowder. 2013. Emerging frontiers in social-ecological systems research for sustainability of small-scale fisheries. Current Opinion in Environmental Sustainability 5:352-357. https://doi.org/10.1016/ j.cosust.2013.06.008

Kleiber, D., L. M. Harris, and A. C. J. Vincent. 2015. Gender and small-scale fisheries: a case for counting women and beyond. Fish and Fisheries 16:547-562. https://doi.org/10.1111/faf.12075

Krause, M., H. Uibrig, and B. Kidane. 2007. Decision modelling for the integration of woody plants in smallholder farms in the central highlands of Ethiopia. Journal of Agriculture and Rural Development in the Tropics and Subtropics 108(1):1-17. [online] URL: https://www.jarts.info/index.php/jarts/article/view/105/96

Lowitt, K., G. M. Hickey, A. Saint Ville, K. Raeburn, T. Thompson-Colón, S. Laszlo, and L. E. Phillip. 2015. Factors affecting the innovation potential of smallholder farmers in the Caribbean Community. Regional Environmental Change 15:1367-1377. https://doi.org/10.1007/s10113-015-0805-2

Macintyre, M., and S. Foale. 2013. Science, traditional ecological knowledge and anthropology: managing the impacts of mining in Papua New Guinea. Collaborative Anthropologies 6:399-418. https://doi.org/10.1353/cla.2013.0024 
MacVaugh, J., and F. Schiavone. 2010. Limits to the diffusion of innovation: a literature review and integrative model. European Journal of Innovation Management 13:197-221. https://doi. org/10.1108/14601061011040258

Mangubhai, S, W. Lalavanua, and S. W. Purcell. 2017. Fiji's sea cucumber fishery: advances in science for improved management. Report No. 01/17. Wildlife Conservation Society, Suva, Fiji. [online] URL: https://www.researchgate.net/publication/314771808_Fiji's_Sea_Cucumber_Fishery_Advances_in_Science_for_Improved Management

Matata, P., O. C. Ajay, P. A. Oduol, and A. Agumya. 2010. Socioeconomic factors influencing adoption of improved fallow practices among smallholder farmers in western Tanzania. African Journal of Agricultural Research 5(8):818-823.

Meijer, S. S., D. Catacutan, O. C. Ajayi, G. W. Sileshi, and M. Nieuwenhuis. 2015. The role of knowledge, attitudes and perceptions in the uptake of agricultural and agroforestry innovations among smallholder farmers in sub-Saharan Africa. International Journal of Agricultural Sustainability 13:40-54. https://doi.org/10.1080/14735903.2014.912493

Purcell, S. W. 2014. Processing sea cucumbers into bêche-de-mer: a manual for Pacific Island fishers. Southern Cross University, Lismore, Australia, and the Secretariat of the Pacific Community, Noumea. New Caledonia. [online] URL: https://www.aciar.gov. $\underline{\mathrm{au} / \text { file/81256/download?token }=X \mathrm{XD17ejx}}$

Purcell, S. W., B. I. Crona, W. Lalavanua, and H. Eriksson. 2017. Distribution of economic returns in small-scale fisheries for international markets: a value-chain analysis. Marine Policy 86:9-16. https://doi.org/10.1016/j.marpol.2017.09.001

Purcell, S. W., P. Ngaluafe, S. J. Foale, N. Cocks, B. R. Cullis, and W. Lalavanua. 2016a. Multiple factors affect socioeconomics and wellbeing of artisanal sea cucumber fishers. PLoS ONE 11(12): e0165633. https://doi.org/10.1371/journal.pone.0165633

Purcell, S. W., P. Ngaluafe, K. T. Aram, and W. Lalavanua. $2016 b$. Trends in small-scale artisanal fishing of sea cucumbers in Oceania. Fisheries Research 183:99-110. https://doi.org/10.1016/ j.fishres.2016.05.010

Purcell, S. W., P. Ngaluafe, K. T. Aram, and W. Lalavanua. $2016 c$. Variation in postharvest processing of sea cucumbers by fishers and commercial processors among three Pacific Island countries. SPC Bêche-de-mer Information Bulletin 36:58-66.

Purcell, S. W., A. Mercier, C. Conand, J.-F. Hamel, M. V. ToralGranda, A. Lovatelli, and S. Uthicke. 2013. Sea cucumber fisheries: global analysis of stocks, management measures and drivers of overfishing. Fish and Fisheries 14:34-59. https://doi. org/10.1111/j.1467-2979.2011.00443.x

Purcell, S. W., D. H. Williamson, and P. Ngaluafe. 2018. Chinese market prices of bêche-de-mer: implications for fisheries and aquaculture. Marine Policy 91:58-65. https://doi.org/10.1016/j. marpol.2018.02.005

Ram, R., R. V. Chand, and P. C. Southgate. 2014. Effects of processing methods on the value of bêche-de-mer from the Fiji Islands. Journal of Marine Science: Research and Development 4:1-7. [online] URL: https://www.omicsonline.org/open-access/ effects-of-processing-methods-on-the-value-of-bchedemer-fromthe-fiji-islands-2155-9910.1000152.php?aid=34252

R Core Team. 2018. R: a language and environment for statistical computing. Version 3.5.1. R Foundation for Statistical Computing, Vienna, Austria. [online] URL: https://www.rproject.org/about.html

Roeger, J., S. Foale, and M. Sheaves. 2016. When 'fishing down the food chain' results in improved food security: evidence from a small pelagic fishery in Solomon Islands. Fisheries Research 174:250-259. https://doi.org/10.1016/j.fishres.2015.10.016

Rogers, E. M. 2003. Diffusion of innovations. Free, New York, New York, USA.

Santucci, F. M. 2005. Strategic communication for rural development. World Bank, Washington, D.C., USA. [online] URL: http://siteresources.worldbank.org/EXTDEVCOMMENG/ Resources/strategiccommruralfinal.pdf

Thomas, M., and S. Caillon. 2016. Effects of farmer social status and plant biocultural value on seed circulation networks in Vanuatu. Ecology and Society 21(2):13. https://doi.org/10.5751/ ES-08378-210213 
Appendix 1 - Supplementary Information

Table A1.1 Summary statistics of respondents of fisher surveys.

\begin{tabular}{|c|c|c|c|c|c|}
\hline Location/village & Mean age $( \pm S D)$ & $\begin{array}{l}\text { Percentage } \\
\text { processing } \\
\text { their catch }\end{array}$ & $\begin{array}{l}\text { No. men } \\
\text { surveyed }\end{array}$ & $\begin{array}{l}\text { No. women } \\
\text { surveyed }\end{array}$ & $\begin{array}{c}\text { Village } \\
\text { population }\end{array}$ \\
\hline \multicolumn{6}{|l|}{ Bua } \\
\hline Galoa (Bua) & $39(11)$ & 85 & 6 & 7 & 240 \\
\hline Yadua & $38(9)$ & 30 & 6 & 4 & 180 \\
\hline Yaqaga & $34(9)$ & 58 & 7 & 5 & 152 \\
\hline \multicolumn{6}{|l|}{ Cakaudrove } \\
\hline Nanuca & $43(11)$ & 9 & 7 & 4 & 120 \\
\hline Tacilevu & $41(9)$ & 0 & 3 & 10 & 427 \\
\hline Vunisavisavi & $40(13)$ & 47 & 8 & 7 & 35 \\
\hline \multicolumn{6}{|l|}{ Kadavu } \\
\hline $\begin{array}{c}\text { Galoa } \\
\text { (Kadavu) }\end{array}$ & $40(11)$ & 0 & 6 & 3 & 140 \\
\hline Matanuku & $45(13)$ & 73 & 5 & 6 & 67 \\
\hline Muani & $50(10)$ & 27 & 1 & 10 & 275 \\
\hline Narikoso & $35(12)$ & 0 & 7 & 4 & 108 \\
\hline Vabea & $34(10)$ & 0 & 7 & 3 & 76 \\
\hline \multicolumn{6}{|l|}{ Lau (South) } \\
\hline Dakuiloa & $34(10)$ & 14 & 11 & 3 & 67 \\
\hline Tubou & $40(11)$ & 43 & 3 & 4 & 627 \\
\hline Waciwaci & $42(11)$ & 11 & 8 & 1 & 120 \\
\hline Waiqori & $31(11)$ & 13 & 8 & 0 & 85 \\
\hline Waitabu & $30(10)$ & 56 & 7 & 2 & 145 \\
\hline \multicolumn{6}{|l|}{$\mathrm{Ra}$} \\
\hline Drauniivi & $42(17)$ & 0 & 7 & 1 & 680 \\
\hline Malake & $33(7)$ & 0 & 10 & 3 & 1153 \\
\hline Togovere & $42(11)$ & 0 & 5 & 6 & 300 \\
\hline \multicolumn{6}{|l|}{ Taveuni } \\
\hline Dreketi & $34(6)$ & 33 & 3 & 0 & 260 \\
\hline Lavena & $38(8)$ & 36 & 4 & 7 & 535 \\
\hline Naselesele & $44(12)$ & 100 & 2 & 7 & 300 \\
\hline Qeleni & $45(12)$ & 100 & 2 & 8 & 338 \\
\hline Vuna & $32(3)$ & 100 & 2 & 0 & 402 \\
\hline \multicolumn{6}{|l|}{ Vanua Balavu } \\
\hline Avea & $33(14)$ & 0 & 11 & 0 & 120 \\
\hline Cikobia & $32(7)$ & 0 & 9 & 0 & 62 \\
\hline Daliconi & $32(9)$ & 13 & 8 & 0 & 108 \\
\hline Mavana & 57 & 100 & 1 & 0 & 215 \\
\hline Narocivo & $31(9)$ & 22 & 6 & 3 & 96 \\
\hline Overall & $38(12)$ & 29 & 170 & 108 & \\
\hline
\end{tabular}


Text A1.2 - Model specification and diagnostics

Prior to the Bayesian analyses, covariates were checked for collinearity by calculating correlation coefficients and variance inflation factors. Models with a binomial response variable were fit using a binomial error distribution, with $\sim$ Cauchy $(0,2.5)$ priors for the covariates and a Cauchy $(0,10)$ intercept (Gelman et al. 2008). Models with a continuous response variable were fit using a gaussian error distribution and flat, non-informative $\mathrm{N}(0$, 100) prior distributions for fixed parameters (intercept and covariates).

Model convergence was assessed visually using trace plots (Brooks and Gelman 1998) for three simultaneously running Markov chains of 10000 iterations (including a discarded 5 000 -iteration burn-in) with a thinning rate of 5 to generate 1000 samples from the posterior distribution of each model parameter estimated. To make inferences about (1) the effect of individual and community-scale variables on adoption and diffusion (knowledge sharing), and (2) the relationship between training and the processing methods used, we used highest posterior density medians (for logistic models) and means (for all others) and their associated 95\% Bayesian uncertainty intervals. Means and medians were estimated from stable posterior distributions generated by Markov-chain Monte Carlo sampling from a model run for each parameter.

\section{$\underline{\text { Supplemental references }}$}

Brooks, S. P., and A. Gelman. 1998. General methods for monitoring convergence of iterative simulations. Journal of Computational and Graphical Statistics 7(4):434455.

Gelman, A., A. Jakulin, M. G. Pittau, and Y. S. Su. 2008. A weakly informative default prior distribution for logistic and other regression models. The Annals of Applied Statistics 2(4): 1360-1383. 
Table A1.3. Summary results of Bayesian hierarchical regressions that tested whether trained and untrained fishers differed in the processing methods employed for six harvested sea cucumber species groups: Actinopyga spp. (ACT), Bohadschia spp. (BOH), lollyfish and pinkfish (L \& P), Stichopus spp. (STI), teatfish (TEAT; Holothuria fuscogilva and H. whitmaei), and Thelenota spp (THE). Values are highest posterior density medians (for water temperature, cut location) and means (for first and second cook duration, salt curing duration) and $95 \%$ uncertainty intervals (in parentheses).

\begin{tabular}{cccccc}
\hline \hline Species & Water temperature & Cut location & First cook duration & Second cook duration & Salt curing duration \\
\hline ACT & - & - & $-1.55(-10.38,6.97)$ & $-4.82(-18.37,9.06)$ & $0.49(-0.20,1.22)$ \\
BOH & - & - & $-10.45 *(-17.55,-2.8)$ & $-8.89(-21.17,3.20)$ & $0.57(0.01,1.17)$ \\
L \& P & - & - & $-10.36 *(-18.12,-2.54)$ & $-8.98(-21.67,4.40)$ & $0.41(-0.17,0.98)$ \\
STI & - & - & $-12.38(-26.67,2.15)$ & $-14.12(-1.77,10.73)$ & $-0.20(-0.88,0.49)$ \\
TEAT & - & $-1.06(-3.40,0.77)$ & $-4.12(-13.25,5.32)$ & $-9.69(-27.26,6.64)$ & $-0.31(-0.52,1.15)$ \\
THE & - & $0.24(-1.67,1.99)$ & $-6.46(-18.23,6.25)$ & $-14.27(-35.54,6.19)$ & $0.07(-0.80,1.04)$ \\
All & $-0.03(-1.36,1.17)$ & - & - & - & - \\
\hline
\end{tabular}

* Indicates evidence for differences between trained and untrained fishers, as $95 \%$ uncertainty intervals do not intersect zero. 